\title{
EVALUATION OF INTUBATING CONDITIONS USING SEVOFLURANE WITHOUT USING MUSCLE RELAXANTS
}

\author{
Vankineni Kuchela Babu1, Sushree Rath², Ambati Mohan Rao ${ }^{3}$ \\ ${ }_{1}^{1}$ HOD \& Senior Consultant, Department of Anaesthesiology, Seven Hills Hospital, Visakhapatnam. \\ ${ }^{2}$ Senior Resident, Department of Anaesthesiology, Seven Hills Hospital, Visakhapatnam. \\ ${ }^{3}$ Senior Consultant, Seven Hills Hospital, Visakhapatnam.
}

\section{ABSTRACT}

\section{BACKGROUND}

In healthy paediatric patients undergoing mask induction of general anaesthesia with sevoflurane, the induction time can be significantly shortened without an increase in the frequency of airway or vital sign complications using a high concentration, primed circuit technique compared with a conventional, incremental induction method. The vital capacity-rapid inhalation group primed with sevoflurane $8 \%$ was the fastest with no relevant side effects.(1) Sevoflurane using this technique was very well tolerated, indicated by high haemodynamic stability and a reduced rate of postoperative restlessness, shivering, nausea and vomiting.(2) It has a definite role in predicted difficult airway patients.

\section{MATERIALS AND METHODS}

A prospective randomized controlled study to evaluate intubating conditions using $8 \%$ sevoflurane without any use of muscle relaxants through vital capacity inhalational technique was undertaken in our institute, Seven Hills Hospital, Vishakhapatnam, during the period 2012-2013 on 51 patients aged between 18 to 65 years, belonging to ASA Grade I and II. Time taken for smooth intubation was noted and other induction parameters were observed. During laryngoscopy, evaluation of intubating conditions was done and haemodynamic parameters were noted at different point of time. The time of exposure to the inhaled gas was varied for consecutive participants. It was either increased or decreased by $30 \mathrm{sec}$ increments based on the failure or success of preceding patient's response to laryngoscopy and intubation after a preselected exposure time.

\section{RESULTS}

On assessment of intubating condition during laryngoscopy, it was found that $76.47 \%$ of patients fell into excellent category, $17.64 \%$ of patients fell into good category, rest $5.88 \%$ fell into moderate category. Two patients could not be intubated because of failure of jaw relaxation as it was very tight, so laryngoscopy was impossible. Excellent intubating condition in $76.47 \%$ patients clearly points towards the additional muscle relaxation property of sevoflurane. In this study, we found the time taken to achieve excellent intubating conditions was 195-210 sec. In our study, most common adverse event observed was apnoea. A total of 16 patients (31.37\%) developed apnoea. Next common adverse event of involuntary movements was found in 9 patients (17.64\%). Two patients (3.92\%) desaturated and were intubated using muscle relaxants. There was absence of jaw relaxation in 2 patients (3.92\%). Next were arrhythmia, bronchospasm, laryngospasm, phonation each having incidence of $1.96 \%$ ( 1 patient). In this study, highest complication occurred in age group of 38-47 years. A total of 5 patients were given muscle relaxants and then intubated as 1 patient developed ventricular ectopics, 2 patients desaturated and in 2 patients it was difficult to intubate.

No adverse events were observed in any patient in our study during maintenance period and extubation. All the patients had a smooth extubation and recovery.

\section{CONCLUSION}

Results of our study concluded that there was a fall of SBP and DBP just before intubation and gradually haemodynamic parameters returned approximately to baseline maintaining haemodynamic stability. However, there was an increase in heart rate. From our study it was found that females took more time for induction as compared to males, except the time taken for jaw relaxation which was more in males. It was also concluded that as age increases (upto age of 47 years) the time taken for induction also increases. Here, in this study we found out the time taken to achieve excellent intubating conditions was around 195-210 sec.

\section{KEYWORDS}

Intubation, Sevoflurane, Vital Capacity Rapid Inhalational Technique.

HOW TO CITE THIS ARTICLE: Babu VK, Rath S, Rao AM. Evaluation of intubating conditions using sevoflurane without using muscle relaxants. J. Evolution Med. Dent. Sci. 2016;5(22):1165-1171, DOI: 10.14260/jemds/2016/271

Financial or Other, Competing Interest: None.

Submission 09-12-2015, Peer Review 29-02-2016,

Acceptance 05-03-2016, Published 16-03-2016.

Corresponding Author:

Dr. Vankineni Kuchela Babu,

HOD \& Senior Consultant,

Department of Anaesthesiology,

Seven Hills Hospital,

Visakhapatnam-2,

Andhra Pradesh.

E-mail: kuchelababu@yahoo.com

DOI: $10.14260 /$ jemds $/ 2016 / 271$

\section{INTRODUCTION}

Tracheal intubation is usually facilitated by administering a muscle relaxant to supplement the drugs given for induction of general anaesthesia. However, if muscle relaxants are avoided the potential complications of their use, misuse and antagonism are prevented. In addition, there is a potential for a rapid return of spontaneous ventilation when inhalation agents is used for induction and intubation without neuromuscular blockade. Inhalation induction is hardly a new concept, dating back to the days of Wells and Morton.(3) 
Even when intravenous alternatives became available, the technique was kept alive by rapid-onset, short-acting anaesthetics such as ethyl chloride, divinyl ether and cyclopropane. But by the 1980s, inhalation induction was used primarily for children and was most unusual in adults. The advent of newer, insoluble volatile anaesthetics reawakened interest in inhalation induction. (3)

Tracheal intubation during deep inhalation has been practiced since anaesthesia began. Renewed interest in adult inhalation induction began during the development of desflurane, which was associated with rapid loss of consciousness in healthy young male volunteers.(4) In clinical use, however, it was found to have an unacceptably high level of coughing and laryngospasm.(5) Although these side effects can be somewhat reduced by pre-treatment with morphine.(6) this is rather impractical and desflurane is rarely used for induction of anaesthesia. In contrast, sevoflurane has a less pungent, fruitier smell and permits a much smoother induction of anaesthesia with a remarkable absence of airway irritability.(7) It reduces mean arterial pressure by several effects on cardiovascular system.

These include peripheral vasodilatation..$^{(8)}$ and decreased sympathetic nervous system activity.(9) Sevoflurane has low blood gas partition coefficient of 0.6, which allows rapid changes in alveolar concentrations and therefore arterial blood pressure can be manipulated promptly.

Moreover, the arrhythmogenicity with epinephrine is lower than other inhalation agents.(10) Sevoflurane with low blood gas solubility allows rapid and early emergence.(11) Sevoflurane also causes less myocardial depression.(12) and bradycardia than Halothane and is probably the volatile agent of choice for inhalation induction in children.(13) High concentrations are tolerated from the outset and opioid pretreatment is unnecessary.

Successful inhalation induction requires an agent of low solubility, reasonable potency and minimal irritation.(14) Because sevoflurane has the best combination of these properties, it makes inhalation induction practical. This produces a number of benefits including good control of the airway, excellent oxygenation, minimal apnoea and less hypotension compared to propofol.(15) Needle phobia is common in children because needles hurt. Needle phobia may affect as many as $10 \%$ of adults.(16)

Traditionally, inhalation induction has been taught using a slow, step-wise increase in inspired concentration. This technique is best avoided with sevoflurane, as it delays induction and increases complications. Both vital capacity.(17) and tidal breathing.(18) techniques with $8 \%$ sevoflurane are rapid and effective with little to choose between the two methods in routine practice. ${ }^{(19)}$

Assuming an inhaled anaesthetic is to be used for maintenance, inhalation induction offers the additional advantage of eliminating the transition from intravenous to inhaled drugs, eliminating what is in effect a second induction. This can reduce the amount of vapour and cost, which is used during the maintenance period.(20) Starting with an inhalation induction represents the most efficient way of delivering a volatile anaesthetic.

Although, low flows are desirable during maintenance, higher flows are necessary during induction because of the high uptake of anaesthetic.
A fresh gas flow of 6 litres per minute is widely used in adults. Higher fresh gas flows may wash anaesthetic into the breathing circuit and alveoli faster, speeding induction, while lower flows should delay induction.

The cost per minute will change linearly with flow, but the total cost will also depend on induction time. The optimal gas flow should induce anaesthesia in an acceptable time, but at minimal cost, produced almost identical results, although other fresh gas flows were not examined.(3)

\section{AIMS AND OBJECTIVES}

1. To evaluate intubating condition with $8 \%$ Sevoflurane without using muscle relaxants with vital capacity rapid inhalational technique.

2. To obtain clinically acceptable intubating conditions without use of muscle relaxants.

\section{METHODOLOGY}

The following prospective randomized controlled study was conducted on 51 human volunteers belonging to ASA Grade I and II of either sex, between 18 to 65 years of age. The nature of study and procedure was explained to the patients and informed written consent were taken from the patients and institutional ethical clearance was obtained.

Pre-operative history taking and clinical examination were done on the day before study. Special emphasis was given on airway examination. Routine investigations were done in all the patients. The investigations includedHaemoglobin, TC, DC, ESR, Blood Urea, Serum Creatinine, Screening profile, ECG if more than 50 years of age, Chest Xray, Liver function tests, Random blood sugar.

\section{Inclusion Criteria}

Patient age 18-65 years.

ASA Grade I or II.

Mallampati Grade I or II.

NPO for 8 hours.

\section{Exclusion Criteria}

Unwilling Candidates.

Patients with Grade II hypertension, hypotension or uncontrolled diabetes.

Age $<18$ and $>65$ years.

Patients with history of bronchial asthma, any reactive airway disease. Patient taking narcotics or drugs, which interfere with neuromuscular transmission.

Patients with history of previously documented difficult intubation.

Patients with coronary artery disease, renal failure, neuromuscular disease, hepatic impairment.

Patients with BMI $>30$.

Patients with known history of gastroesophageal reflux disease.

Patient with known genetic predisposition to malignant hyperthermia, any history of allergic reactions to inhalation agents.

Patients with increase ICP.

Patient with myasthenia gravis.

Patient in labour, obstetrics delivery.

\section{Study Method}

The sample size of 51 cases is considered not too small or too large in order to have a normal Gaussian distribution and to have a proper $P$ value calculated. 
Formula used for this is $\mathrm{n}_{0}=\mathrm{Z}^{2} \mathrm{Pq} / \mathrm{e}^{2}$ where $\mathrm{Z}=1.96, \mathrm{P}=$ $0.5, \mathrm{q}=(1-\mathrm{P})=0.5, \mathrm{e}=15 \%, \mathrm{n}_{0}=$ sample size approximately 43 . So, 51 is a good sample size.

\section{Anaesthetic Management}

The night before surgery each patient was advised Tab. Ranitidine 150 mg PO, Tab. Alprazolam 0.25 mg PO.

\section{Monitoring}

Immediately after the arrival of the patient into the operating room and after intravenous cannulation, all the necessary monitoring apparatus was connected to the patient before induction. From the start of surgery till the time of extubation, the following parameters were measured and recorded.

Electrocardiogram (Lead II and V).

Heart rate.

Oxygen saturation using pulse oximetry.

End tidal carbon dioxide using side stream capnogram.

Skin temperature.

Respiratory rate.

Non-invasive blood pressure.

\section{Premedication}

The baseline vital parameters were noted and then the following drugs were administered- Inj. Ranitidine $0.3 \mathrm{mg} / \mathrm{kg}$, intravenous Inj. Glycopyrrolate $5 \mu \mathrm{g} / \mathrm{kg}$, Inj. Midazolam 0.02 $\mathrm{mg} / \mathrm{kg}$ and Inj. Fentanyl $2 \mu \mathrm{g} / \mathrm{kg}$, one after the other as slow IV bolus in the same order.

A $10 \mathrm{~mL} / \mathrm{kg}$ of ringer lactate solution was given just before induction. After giving Inj. Fentanyl, patients were watched for apnoea, oxygen saturation. Pre-oxygenation was then done for 5 minutes by attaching a mask with nonbreathing valve with reservoir bag to deliver $100 \%$ oxygen by a flow meter with separate source. Hemodynamic responses were recorded and priming of anaesthetic circuit was done for 45 secs with sevoflurane $8 \%, 66 \%$ nitrous oxide/33\% oxygen, i.e. the anaesthetic machine was set to deliver 2 $\mathrm{L} /$ min of oxygen, $4 \mathrm{~L} / \mathrm{min}$ of nitrous oxygen and sevoflurane vaporiser was set to deliver $8 \%$. All patients were then asked to begin vital capacity breathing (Maximal inspiration following maximal expiration) and then take as large a breath as possible from the face mask connected to anaesthetic breathing system and hold their breath for as long as possible from the breathing circuit. This is called vital capacity rapid inhalation technique. The following parameters were noted in seconds during this procedure:

Time interval in seconds.

Start of induction to onset of regular respiration.

Start of induction to loss of eye lash reflex.

Start of induction to jaw relaxation.

Start of induction to centralization of eye balls.

Time required for achieving excellent intubating conditions was noted and laryngoscopy and intubation was done. For success, maximum two attempts of laryngoscopy were done. All male patients were intubated with Portex cuffed endotracheal tube no. $8.0 \mathrm{~mm}$ and female patients with no. $7.0 \mathrm{~mm}$.

Intubating conditions.(21) were assessed as follows:

\begin{tabular}{|l|l|l|}
\hline Criteria & Conditions & Score \\
\hline Jaw relaxation & Fully relaxed & 1 \\
\hline & Mild resistance & 2 \\
\hline & Tight but open & 3 \\
\hline & Impossible & 4 \\
\hline Vocal cord position & Widely open & 1 \\
\hline & Mid position & 2 \\
\hline & $\begin{array}{l}\text { Moving but } \\
\text { open }\end{array}$ & 3 \\
\hline & Closed & 4 \\
\hline Intubation response & None & 1 \\
\hline & $\begin{array}{l}\text { Diaphragmatic } \\
\text { movements }\end{array}$ & 2 \\
\hline & Slight coughing & 3 \\
\hline & Severe coughing & 4 \\
\hline
\end{tabular}

Excellent-score $=3$.

Good-score-4-6.

Moderate-score $>7$.

Clinically acceptable intubating conditions= excellent+good. Haemodynamic responses were recorded at following stages- baseline value, after premedication, at $5 \mathrm{~min}$ after Inj. Fentanyl, pre-intubation, post-intubation (Immediately after intubation), 1 min after intubation, 5 mins after intubation. If patients could not be intubated, they were given muscle relaxant to facilitate intubation. Following intubation, anaesthesia was maintained at the discretion of attending anaesthesiologist.

Some precautions were taken during the whole procedure, i.e. if patient developed apnoea some assisted breaths were given. If patient got desaturated or patient developed arrhythmia, the procedure was abandoned and patient was intubated. The results obtained from the study were depicted in a tabulated form. Statistical analysis was done using the student paired " $\mathrm{t}$ " test.

\section{OBSERVATION AND RESULTS}

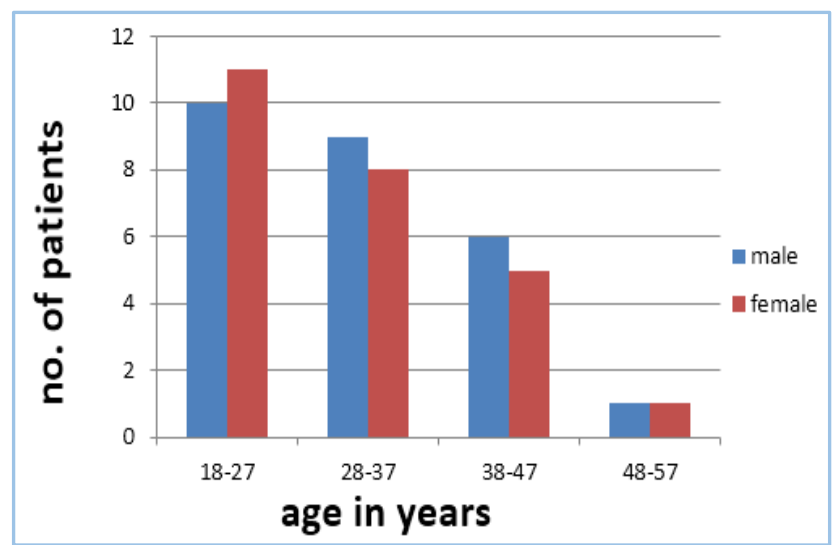

Fig. 1: Showing age Group Distribution and the No. of Males and Females in each Age Group 


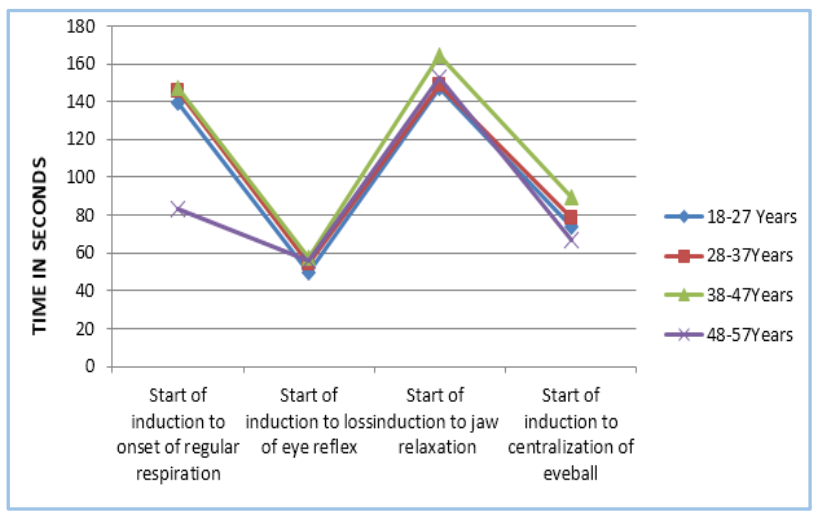

Fig. 2: Showing Comparison of Induction Parameters in Different Age Groups

\begin{tabular}{|c|c|c|c|c|}
\hline $\begin{array}{c}\text { Parameters } \\
\text { (Seconds) }\end{array}$ & Male & Female & $\begin{array}{c}P \\
\text { value }\end{array}$ & $\begin{array}{c}\text { Statistical } \\
\text { Significance }\end{array}$ \\
\hline $\begin{array}{l}\text { Start of } \\
\text { induction to } \\
\text { onset of } \\
\text { regular } \\
\text { respiration }\end{array}$ & $\begin{array}{c}138.33 \pm \\
54.43\end{array}$ & $\begin{array}{c}141.3 \pm \\
46.86\end{array}$ & 0.62 & NS \\
\hline $\begin{array}{l}\text { Start of } \\
\text { induction to } \\
\text { loss of eye } \\
\text { reflex }\end{array}$ & $\begin{array}{c}51.19 \pm \\
15.60\end{array}$ & $\begin{array}{c}54.64 \pm \\
10.84\end{array}$ & 0.47 & NS \\
\hline $\begin{array}{c}\text { Start of } \\
\text { induction to } \\
\text { jaw } \\
\text { relaxation }\end{array}$ & $\begin{array}{c}151.16 \pm \\
44.79\end{array}$ & $\begin{array}{c}149.625 \\
\pm 43.27\end{array}$ & 0.939 & NS \\
\hline $\begin{array}{c}\text { Start of } \\
\text { induction to } \\
\text { centralizatio } \\
\text { n of eyeball }\end{array}$ & $\begin{array}{c}77.61 \pm \\
24.01\end{array}$ & $\begin{array}{l}82.28 \pm \\
21.04\end{array}$ & 0.53 & NS \\
\hline
\end{tabular}

Parameters in Male and Female (Mean \pm SD)

\begin{tabular}{|c|c|c|c|c|}
\hline $\begin{array}{c}\text { Parameters } \\
\text { (Seconds) }\end{array}$ & $\begin{array}{l}18-27 \\
\text { years }\end{array}$ & $\begin{array}{l}28-37 \\
\text { years }\end{array}$ & $\begin{array}{l}38-47 \\
\text { years }\end{array}$ & $\begin{array}{l}48-57 \\
\text { years }\end{array}$ \\
\hline $\begin{array}{l}\text { Start of } \\
\text { induction to } \\
\text { onset of } \\
\text { regular } \\
\text { respiration }\end{array}$ & $\begin{array}{l}139.14 \pm \\
37.02\end{array}$ & $\begin{array}{c}145.30 \pm \\
45.98\end{array}$ & $\begin{array}{c}146.77 \pm \\
71.44\end{array}$ & $\begin{array}{l}83.5 \pm \\
33.23\end{array}$ \\
\hline $\begin{array}{c}\text { Start of } \\
\text { induction to } \\
\text { loss of eye } \\
\text { reflex }\end{array}$ & $\begin{array}{l}49.47 \pm \\
14.55\end{array}$ & $\begin{array}{c}54.58 \pm \\
15.28\end{array}$ & $\begin{array}{c}57.09 \pm \\
8.37\end{array}$ & $56 \pm 5.65$ \\
\hline $\begin{array}{c}\text { Start of } \\
\text { induction to } \\
\text { jaw } \\
\text { relaxation }\end{array}$ & $\begin{array}{c}146.80 \pm \\
39.36\end{array}$ & $\begin{array}{c}148.62 \pm \\
25.29\end{array}$ & $\begin{array}{l}164.66 \pm \\
73.95\end{array}$ & $\begin{array}{c}152.5 \pm \\
38.89\end{array}$ \\
\hline $\begin{array}{c}\text { Start of } \\
\text { induction to } \\
\text { centralization } \\
\text { of eyeball }\end{array}$ & $\begin{array}{c}74.09 \pm \\
18.48\end{array}$ & $\begin{array}{c}78.38 \pm \\
18.61\end{array}$ & $\begin{array}{c}89.45 \pm \\
24.65\end{array}$ & $67 \pm 18.38$ \\
\hline \multicolumn{5}{|c|}{$\begin{array}{l}\text { Table 2: Comparison of Induction } \\
\text { Parameters in all Age Groups }\end{array}$} \\
\hline
\end{tabular}

\begin{tabular}{|c|c|c|c|c|}
\hline $\begin{array}{c}\text { Haemodynamic parameters at } \\
\text { different point of time }\end{array}$ & $\begin{array}{c}\text { SBP (mean systolic blood } \\
\text { pressure in mmHg) } \pm \text { SD }\end{array}$ & $\begin{array}{c}\text { DBP } \\
\text { (mean diastolic blood } \\
\text { pressure in mmHg) } \pm \text { SD }\end{array}$ & $\begin{array}{c}\text { PULSE RATE per } \\
\text { min (mean } \pm \text { SD) }\end{array}$ & $\begin{array}{c}\text { SPO2 in\% } \\
\text { (mean } \pm \text { SD) }\end{array}$ \\
\hline Baseline & $123.84 \pm 14.22$ & $75.37 \pm 12.07$ & $82.74 \pm 14.54$ & $100 \pm 0$ \\
\hline After premedication & $123.39 \pm 14.50$ & $75.82 \pm 11.76$ & $84.35 \pm 16.21$ & $99.86 \pm 0.980$ \\
\hline $\begin{array}{c}\text { At 5 minutes after injection } \\
\text { fentanyl }\end{array}$ & $118.78 \pm 13.70$ & $72.35 \pm 14.25$ & $83.41 \pm 17.57$ & $99.7 \pm 1.55$ \\
\hline Pre-intubation & $113 . \pm 18.61$ & $71.03 \pm 15.95$ & $86.86 \pm 18.83$ & $98.92 \pm 3.38$ \\
\hline $\begin{array}{c}\text { Post intubation (Immediately } \\
\text { after intubation) }\end{array}$ & $120 \pm 23.43$ & $78.66 \pm 17.90$ & $98.27 \pm 21.74$ & $99.37 \pm 1.44$ \\
\hline 1 minute after intubation & $116.82 \pm 19.59$ & $73.21 \pm 15.45$ & $93.88 \pm 17.52$ & $99.88 \pm 0.475$ \\
\hline 5 minutes after intubation & $110.82 \pm 11.946$ & $70.78 \pm 12.39$ & $86.84 \pm 16.70$ & $99.96 \pm 0.196$ \\
\hline & Table 5: Showing Haemodynamic Parameters at Different Point of Time & \\
\hline
\end{tabular}




\begin{tabular}{|c|c|c|}
\hline Complication & $\begin{array}{c}\text { No. of } \\
\text { Patients }\end{array}$ & $\mathbf{\%}$ \\
\hline APNOEA & 16 & 31.37 \\
\hline INVOLUNTARY MOVEMENTS & 9 & 17.64 \\
\hline ARRHYTHMIA & 1 & 1.96 \\
\hline BRONCHOSPASM & 1 & 1.96 \\
\hline PHONATION & 1 & 1.96 \\
\hline LARYNGOSPASM & 1 & 1.96 \\
\hline DBSENSE OF JAW RELAXATION & 2 & 3.92 \\
\hline Table 6: Showing Incidence of Different Complications \\
\hline
\end{tabular}

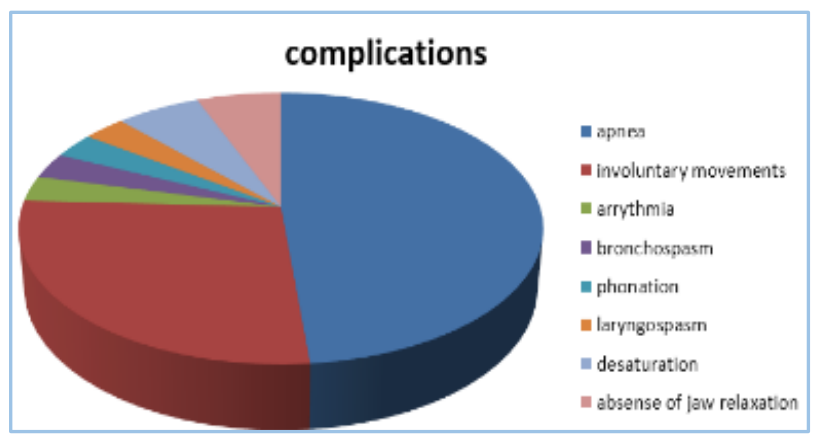

Fig. 5: Showing Incidence of Different Complications

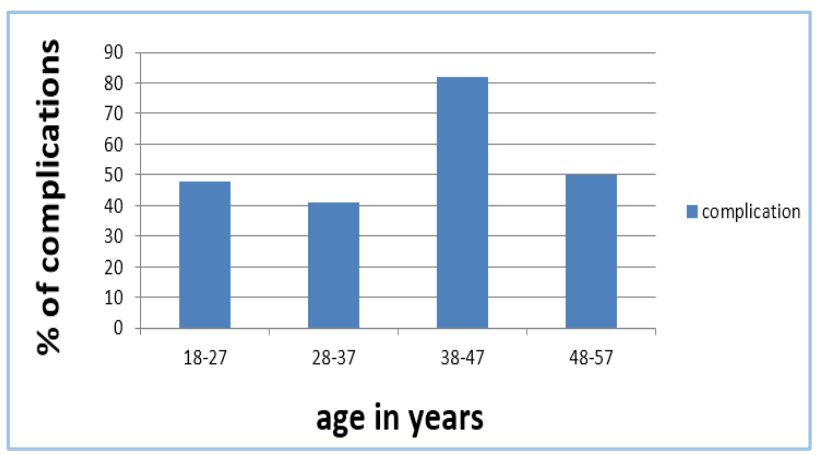

Fig. 6: Showing Incidence of Complications in Different Age Groups

NS: Not Significant.

NQS: Not Quite Significant.

VS: Very Significant.

S: Significant.

ES: Extremely Significant.

\section{DISCUSSION}

Sevoflurane is a recent addition as inhalational agent for induction in adults. Due to its low pungency, low blood gas solubility, limited cardiorespiratory depression, faster induction and recovery it is desirable for use as induction agent.

Due to low blood gas, solubility of sevoflurane induction is faster. Jaw relaxation was considered as end point of induction. Black et al.(22) also found that time required to achieve eyeball centralization was faster in sevoflurane.

a) Mean Time Taken from Induction to Onset of Regular Respiration

In males it was $138.33 \pm 54.43$ seconds and in females $141.3 \pm 46.86$ seconds. P value between the two groups in comparison was 0.62 , which was considered not significant. Mean time taken from induction to onset of regular respiration in 18-27 years' age group was
$139.14 \pm 37.02$ seconds. In $28-37$ years' age group was $145.30 \pm 45.98$ seconds.

In $38-47$ years' age group was $146.77 \pm 71.44$ seconds. In 48-57 years was $83.5 \pm 33.23$ seconds.

Out of 51 patients there was no onset of regular respiration in 16 patients $(31.37 \%)$, as these patients went into apnoea and assisted breaths were given.

\section{b) Mean Time Taken from Start of Induction to Loss of Eyelash Reflex}

In males was $51.19 \pm 15.60$ seconds and in females was $54.64 \pm 10.84$ seconds. P value between the two groups in comparison was 0.47, which was considered not significant. Mean time taken from induction to loss of eyelash reflex in 18-27 years' age group was around $49.47 \pm 14.55$ seconds. In $28-37$ years' age group was around $54.58 \pm 15.28$ seconds. In $38-47$ years was $57.09 \pm 8.37$ seconds. In $48-57$ years was $56.0 \pm 5.65$ seconds.

This short induction time (Loss of unconsciousness) in case of this anaesthetic agent can make it to be used in conditions where rapid sequence induction is required.

\section{c) Mean Time Taken from Start of Induction to Jaw} Relaxation

In males it was $151.16 \pm 44.79$ seconds and in females $149.62 \pm 43.27$ seconds.

$P$ value between the two groups in comparison was 0.939 , which was considered not significant. Mean time taken from induction to jaw relaxation in 18-27 years' age group was $146.80 \pm 39.36$ seconds. In 28-37 years' age group was $148.62 \pm 25.29$ seconds. In $38-47$ years was $164.66 \pm 73.95$ seconds. In $48-57$ years was $152.5 \pm 38.89$ seconds. Jaw relaxation was not seen in two patients, out of which one was male other was female. Muscle relaxant was then supplemented and then the patients were intubated.

\section{d) Mean Time Taken from Start of Induction to Centralization of Eyeballs}

In males was around $77.61 \pm 24.01$ seconds and in females was around $82.28 \pm 21.04$ seconds. $P$ value between the two groups in comparison was around 0.53 , which was considered not significant. Mean time taken from induction to centralization of eyeballs in 18-27 years' age group was around $74.09 \pm 18.48$ seconds. In $28-37$ years' age group was around $78.38 \pm 18.61$ seconds. In 38-47 years was $89.45 \pm 24.65$ seconds. In $48-57$ years was $67 \pm 18.38$ seconds.

It was found that time taken by females for induction was more compared to males except jaw relaxation, which was more in males. Secondly, it was found that as age increases (upto age of 47 years) time taken for induction increases as seen in all four induction parameters.

\section{Dr. Choudhury M, Dr. Kiran U, Dr. Saxena N.(23)}

Made a comparison of sevoflurane with thiopentone and found sevoflurane vital capacity inhalational induction suitable for patients undergoing coronary artery bypass grafting surgery on 40 patients and the results were as follows: $95 \%$ of the patients fell into excellent category, $5 \%$ in good category.

Excellent intubating condition in $76.47 \%$ patients clearly points towards the additional muscle relaxation property of sevoflurane.

The time of exposure to the inhaled gas was varied for consecutive participants. It was either increased or decreased 
by $30 \mathrm{sec}$ increments based on the failure or success of preceding patient's response to laryngoscopy and intubation after a preselected exposure time. Here, in this study at around approximately 195-210 seconds excellent intubating conditions were achieved.

\section{SBP}

Before induction mean baseline SBP was $123.84 \pm 14.22 \mathrm{mmHg}$. Pre-intubation SBP was $113 \pm 18.61 \mathrm{mmHg}$. There was a fall of $10 \mathrm{mmHg}$ approximately as compared to baseline. Mean post intubation (Immediately after intubation) SBP was $120 \pm 23.43$ $\mathrm{mmHg}$. There was a fall of $3 \mathrm{mmHg}$ approximately compared to baseline.

Mean SBP after 1 minute of intubation was $116.82 \pm 19.59$ $\mathrm{mmHg}$. There was a fall of $7 \mathrm{mmHg}$ approximately compared to baseline.

\section{DBP}

Before induction mean baseline DBP was $75.37 \pm 12.07 \mathrm{mmHg}$. Pre-intubation DBP was $71.03 \pm 15.95 \mathrm{mmHg}$. There was a fall of $4 \mathrm{mmHg}$ approximately as compared to baseline. Mean postintubation (Immediately after intubation) DBP was $78.66 \pm 17.90 \mathrm{mmHg}$. There was a rise of $3 \mathrm{mmHg}$ approximately compared to baseline.

Mean DBP after 1 minute of intubation was $73.21 \pm 15.45$ $\mathrm{mmHg}$. There was a fall of $2 \mathrm{mmHg}$ approximately compared to baseline.

\section{HEART RATE}

In a study done by Dr. Kajal N. Dedhia, Dr. Amala Kudalkar on comparison of sevoflurane and halothane for induction of anaesthesia and LMA insertion in paediatric patients found that there was a significant increase in heart rate after 30 seconds in sevoflurane group.(24)

In our study before induction, mean baseline heart rate was $82.74 \pm 14.54 /$ minute. Pre-intubation heart rate was $86.86 \pm 18.83 \mathrm{mmHg}$. There was a rise of heart rate of $4 /$ minute approximately as compared to baseline.

Mean post-intubation (Immediately after intubation) heart rate was $98.27 \pm 21.74$ /minute. There was a rise of heart rate of $16 /$ minute approximately compared to baseline.

Mean heart rate after 1 minute of intubation was $93.88 \pm 17.52 \mathrm{mmHg}$. There was rise of $11 /$ minute approximately compared to baseline.

\section{SPO2}

Before induction mean baseline saturation was $100 \%$. Mean pre-intubation saturation was $98.92 \pm 3.38 \%$.

Mean post-intubation (Immediately after intubation) saturation was $99.37 \pm 1.44 \%$.

Mean saturation after 1 minute of intubation was $99.88 \pm 0.475 \%$.

Use of high concentration of sevoflurane helps faster induction, but is associated with considerable amount of excitement and adverse airway reaction as seen by Sigston et al.(25) who used 8\% Sevoflurane after priming the circuit with Sevoflurane. In our study, most common adverse event was apnoea. A total of 16 patients (31.37\%) developed apnoea. Next common adverse event was involuntary movements, 9 patients (17.64\%) had involuntary movements; 2 patients (3.92\%) developed desaturation.

The procedure was abandoned and the patients were intubated. Next were arrhythmia, bronchospasm, laryngospasm, phonation each having incidence of $1.96 \%$ (1 patient).

There was absence of jaw relaxation in 2 patients (3.92\%). In this study highest complication occurred in age group of 38-47 years. A total of 4 number of patients were intubated in second attempt, rest patients were intubated in first attempt.

No adverse events were observed in any patient in our study during maintenance and extubation. All the patients had a smooth extubation and recovery.

\section{CONCLUSION}

Sevoflurane provided good intubating conditions without using muscle relaxants. It provides rapid induction with better haemodynamic stability perioperatively. It is a suitable alternative in difficult airway patients.

The vital capacity rapid inhalational group primed with Sevoflurane $8 \%$ gave clinically acceptable intubating conditions without use of muscle relaxants. This is a suitable alternative compared to IV induction agents where spontaneous ventilation is provided by induction.

\section{REFERENCES}

1. Martín-Larrauri R, Gilsanz F, Rodrigo J, et al. Conventional stepwise vs. vital capacity rapid inhalation induction at two concentrations of sevoflurane. Eur J Anaesthes 2004;21(4):265-71.

2. Wappler F, Frings DP, Scholz J, et al. Inhalational induction of anaesthesia with $8 \%$ sevoflurane in children: conditions for endotracheal intubation and side-effects. Eur J Anaesthesiol 2003;20(7):548-54.

3. Smith I, Nathanson M, White PF. Sevoflurane-a long awaited volatile anaesthetic. British journal of anesthesia 1996; 76:435-445.

4. Jones RM, Cashman JN, Mant TGK. Clinical impressions and cardiorespiratory effects of a new fluorinated inhalational anaesthetic, desflurane (I-653), in volunteers. Br J Anaesth 1990;64:11-5

5. Van Hemelrijck J, Smith I, White PF. Use of desflurane for outpatient anesthesia: a comparison with propofol and nitrous oxide. Anesthesiology 1991;75:197-203.

6. Kong CF, Chew STH, Ip-Yam PC. Intravenous opioids reduce airway irritation during induction of anaesthesia with desflurane in adults. Br J Anaesth 2000;85:364-7.

7. Thwaites A, Edmends S, Smith I. Inhalation induction with sevoflurane: a double-blind comparison with propofol. Br J Anaesth 1997;78:356-61.

8. Malan TP Jr, Dilnardo JA, Isner, et al. Cardiovascular effects of sevoflurane compared with those of isoflurane in volunteers. Anesthesiology 1995;83:918-28.

9. Yamazaki M, Stekiel TA, Bosnjak ZJ, et al. Effects of volatile anesthetic agents on in situ vascular smooth muscle transmembrane potential in resistance and capacitance regulating blood vessels. Anesthesiology 1998;88:108595.

10. Imamura S, Ikeda K. Comparision of the epinephrine induced arrhythmogenic effects of sevoflurane with isoflurane and halothane. J Anesth 1987;1:62-68.

11. Lerman Jerrold, Nancy Sikich, Sam Kleinman, et al. The pharmacology of sevoflurane in infants and children. Anesthesiology 1994;80:814-824. 
12. Kataria B, Epstein R, Bailey A, et al. A comparison of sevoflurane to halothane in paediatric surgical patients: results of a multicentre international study. Paed Anaesth 1996;6:283-292.

13. Holzman RS, van der Velde ME, Kaus SJ, et al. Sevoflurane depresses myocardial contractility less than halothane during induction of anaesthesia in children. Anesthesiology 1996;85:1260-126.

14. Logan M. A practical review of VIMA techniques. Int Proceed J 1998;7:4-10.

15. Kirkbride DA, Parker JL, Williams GD, et al. Induction of anesthesia in the elderly ambulatory patient: a doubleblind comparison of propofol and sevoflurane. Anesth Analg 2001;93:1185-7.

16. Hamilton JG. Needle phobia: a neglected diagnosis. J Fam Pract 1995;41:169-75.

17. Yurino $M$, Kimura $H$. Induction of anesthesia with sevoflurane, nitrous oxide, and oxygen: a comparison of spontaneous ventilation and vital capacity rapid inhalation induction (VCRII) techniques. Anesth Analg 1993;76:598601.

18. Hall JE, Stewart JIM, Harmer M. Single-breath inhalation induction of sevoflurane anaesthesia with and without nitrous oxide: a feasibility study in adults and comparison with an intravenous bolus of propofol. Anaesthesia 1997;52:410-5.
19. Baker CE, Smith I. Sevoflurane: a comparison between vital capacity and tidal breathing techniques for the induction of anaesthesia and laryngeal mask airway placement. Anaesthesia 1999;54:841-4.

20. Smith I, Terhoeve PA, Hennart D, et al. A multicentre comparison of the costs of anaesthesia with sevoflurane or propofol. Br J Anaesth 1999;83:564-70.

21. Cooper R, Mirakhur RK, Clarke RSJ, et al. Comparison of intubating conditions after administration of org 9426 (Rocuronium) and suxamethonium. $\mathrm{Br} \mathrm{J}$ Anaesth 1992;69:269.

22. Choudhury M, Kiran U, Saxena N. Is sevoflurane vital capacity inhalational induction suitable for patients undergoing coronary artery bypass grafting surgery? a comparison with thiopentone. Indian J Anaesth 2005;49(5):403-408.

23. Black A, Sury MRJ, Haemington L, et al. A comparison of the induction characteristics of sevoflurane and halothane in children. Anaesthesia 1996;51:539-542.

24. Kajal N Dedhia, Amala Kudalkar. Comparision of sevoflurane and halothane for induction of anaesthesia and laryngeal mask insertion in paediatric patients. Indian J Anaesth 2004;48(6):465-468.

25. Sigston PE, Jenkins AMC, Jackson EA, et al. Rapid inhalational induction in children: $8 \%$ sevoflurane compared with 5\% halothane. Br J Anaesth 1997;78:3625 . 